\title{
A REVIEW ARTICLE ON: ANTIBIOTIC RESISTANCE
}

\section{Ajid K. Mule*, Suraj Malpani, Shradha T. Nemane, Sushil S. Kore, Ayaj S. Pathan}

Shivlingeshwar College of Pharmacy Almala Tq. Ausa Dist. Latur, Maharashtra India.

Article Info: Received 18 April 2020; Accepted 10 June 2020

DOI: https://doi.org/10.32553/jbpr.v9i3.763

Corresponding author: Ajid K. Mule

Conflict of interest statement: No conflict of interest

\begin{abstract}
Antibiotics are the 'wonder drugs' to combat microbes. For decades, various types of antibiotics have not only been used for therapeutic purposes but practiced prophylactically across other industries such as agriculture and animal husbandry. Antibiotic-resistant infections correlate with the level of antibiotic consumption. Non-judicial use of antibiotics is one of the reason for making the microbes resistant. The antibiotic therapy store for emerging hard-totreat multidrug-resistant bacterial infections is limited, resulting in high morbidity and mortality report. As per the World Health Organization "First worldwide Report on Antibiotic Resistance", and the U.S. Centers for Disease Control \& Prevention (CDC\&P) and the spread of "superbugs" - bacteria that have changed in ways that provided antibiotics non effective against them - is a severe and growing threat around the world. Once common treatments for not only everyday intestinal and urinary tract infections but also pneumonia as well as infections in newborn and diseases like gonorrhea are no longer working in people. Thus, in 2013, two million people in the U.S. were affected by antibioticresistant bacteria, and 23,000 of them die each year as a result.
\end{abstract}

Keywords: Wonder drugs, antibiotic resistance, CDC\&P, Superbugs etc.

\section{Introduction}

The detection and subsequent clinical introduction of antibiotics is one of the most important game-changers in the history of medicine [1]. These drugs have saved millions of lives from infections that would before have been mortal, and later, they allowed for the introduction of surgical interventions, organ transplantation, care of premature infants, and cancer chemotherapy [2]. Even so, the treatment of bacterial infections is becoming less and less straightforward due to the emergence of multidrug resistance (MDR) in these pathogens [3]. Direct effect of antibiotic resistance involve late in the start of the appropriate (effective) antimicrobial treatment, the need to use older, more toxic antibiotics (e.g., colistin) with a disadvantageous side effect profile, longer hospital stays, and an increasing burden on the healthcare infrastructure; overall, a decrease in the quality-of-life (QoL) and an increase in the mortality rate of the a_ected patients $[4,5]$. To highlight the severity of the issue, several international declarations have been published to call governments around the globe to take action on antimicrobial resistance [6-9].

\section{Antibiotics}

Antibiotics are chemical agents that inhibits bacterial growth by stopping the bacterial cell from dividing (bacteriostatic) or by destroying them (bactericidal). The terms antibiotic and antimicrobial are often used interchangeably but are not synonymous. Antibiotics are substances of microbial origin (such as penicillin) while "antimicrobial" refers to any substance including synthetic compounds which destroys microbes [10].

Antibiotics are used to treat and or prevent disease in human and animals. The reductions in death afforded by effective antibiotics for bacterial infections of all types, ranging from simple skin infections to infections of the bloodstream, lung, abdomen, as well as brain, so enormous that the lives of both human and animals are saved due to treatment by using antibiotics [11].

Table 1: A list of antimicrobial agents and their modes of action

\begin{tabular}{lll}
\hline Antimicrobial agents & Group & Mode of action \\
\hline $\begin{array}{l}\text { Ampicillin, Augmentin, } \\
\text { Amoxycillin }\end{array}$ & Penicillins & Inhibitor of cell wall synthesis \\
\hline Ceftriaxone & Cephalosporins & Inhibitor of cell wall synthesis \\
\hline Chloramphenicol & Chloramphenicol & Inhibitor of protein synthesis \\
\hline Erythromycin & Macrolides & Inhibitor of protein synthesis \\
Azithromycin & & \\
\hline Gentamycin, streptomycin & Aminoglycosides & Inhibitor of protein synthesis \\
\hline Oxytetracycine & Tetracyclines & \\
\hline Nalidixicacid Ciprofloxacin & Quinolones & Inhibitors of DNA synthesis \\
\hline Sulfamethazine, & Sulfonamides & Competitive inhibitors of folic \\
Trimethopim & & acid synthesis \\
\hline
\end{tabular}




\section{Mechanism of action of antibiotics}

In order to appreciate the process of resistance, it is important to understand how antimicrobial agents act. One of the most common mechanisms of action is targeting the cell wall, which is present in bacteria (prokaryotic cells) but absent in humans (eukaryotic cells). Thus, antimicrobial agents act choosily on vital microbial functions with minimal effects or without affecting host functions. Different classes of antibiotics possess specific modes of action by which they inhibit the growth or kill bacteria [12].

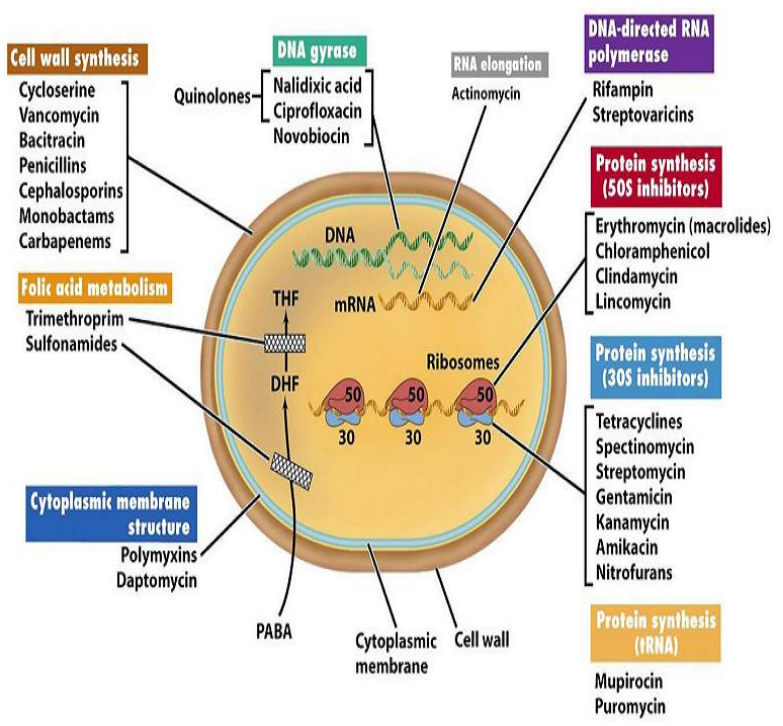

Figure 1: Mechanism of action of antibiotics (Source: http:// www.text book of Brook biology of microorganisms' org.com).

\section{Antibiotic Resistance}

Antibiotic resistance is the capability of a pathogen or other microorganisms to exist and reproduce in the presence of some amount of antibiotic doses that were previously thought effective against them [13]. The origin of antibiotic resistance genes are unclear; however studies using clinical isolates collected before the introduction of antibiotics demonstrated susceptibility, although, conjugative plasmids were present [14].

Normally, most cells in a naive, susceptible bacterial population which can cause an infection are susceptible to particular antibiotic upon exposure. However, there is always a minute sub-population of resistant bacterial cells that will be able to multiply at higher concentrations in insufficient antibiotic concentration which kill the sub population so that micro-organisms survives in the environment [15]. Resistance is often associated with decreased bacterial fitness, and it has been suggested that a decreased in antibiotic use will pose selective pressure to get resistance would afford the fitter susceptible bacteria, enabling them to out compete resistant strains over time [16].

Antibiotic resistant bacteria are a growing general public health emergency since infections from resistant bacteria are more hard and costly to treat. For instance, since the 1990s, some strains of Salmonella became resistant to a range of antibiotics. Resistance is assumed to be occurred from the use of antibiotics in human and animals' husbandry. The major problem in the clinical practice today is the emergence of multiple-drug resistance, which is resistance to several types of antimicrobial agent [17].

\section{Mechanism of antibiotic resistance}

As there are many different ways in which antibiotics can kill or inhibit the growth and multiplication of microorganisms, there are also many mechanisms of resistance that microorganisms innately possess or have developed over time through exposure of antibiotics. It is possible that through one procedure, an organism can become resistant to various different classes of antibiotics, specially if the modes of action are similar. Occasionally resistance can be shared between separate bacteria through the manufacturing of "resistance plasmids," the pieces of DNA able to being transferred from one cell to another [18]. A microorganism is resistant if it exhibits "definite decreased susceptibility" when compared with that of the "original isolate" or collection of delicate strains (Chapman, 1998). Resistance can result from mutations in housekeeping structural or regulatory genes, or alternatively, horizontal acquisition of foreign genetic information [19].
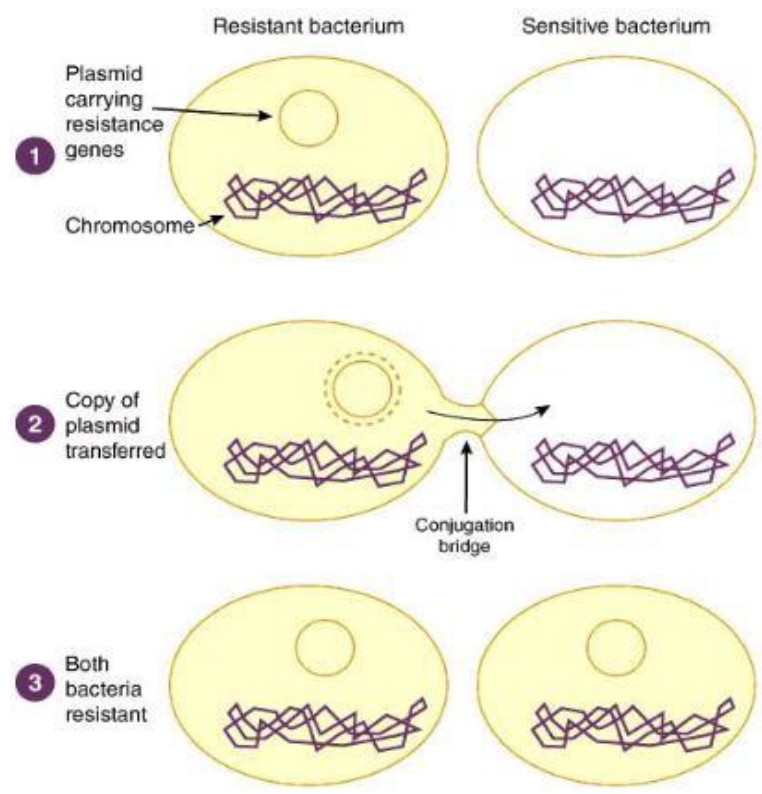

Figure2: Horizontal gene transfer: resistance gene being transferred from one bacterium to another. 


\section{SPREAD OF ANTIBIOTIC RESISTANCE}

SPREAD OF ANTIBIOTIC RESISTANCE

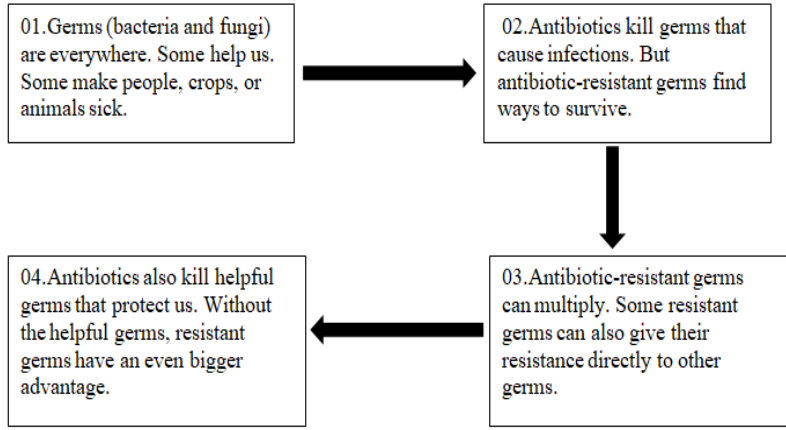

05. Once antibiotic resistance

emerges, it can spread into new

settings and between countries.

\section{Consequence of antibiotic resistance}

Antibiotic resistant organisms are known as superbugs. These are not only a laboratory concern but have become a global threat responsible for high death tolls and life-threatening infections [21]. Consequences of these infections are aggravated enormously in volatile situations such as civil unrest, violence, famine and natural disaster [22]. World Health Organization (WHO) [22] has warned that a post-antibiotic era will result in frequent infections and small injuries may result in death if we fail to act against antibiotic resistance. Multidrug-resistant bacteria causing more deaths worldwide. More than 63,000 patients from the United States of America (USA) die every year from hospitalacquired bacterial infections [23]. Every year, an estimated 25,000 patients die due to multiple drug resistance (MDR) bacterial infections in Europe [24]. Many countries are facing the burden of nosocomial Staphylococcus aureus (S. Aureus) infections as waves of clonal dissemination. Methicillin-resistant Staphylococcus aureus (MRSA) strains are rapidly spreading globally [25]. Estimated costs due to multidrug-resistant bacterial infection might result in extra healthcare costs and productivity losses [24]. It has been a standard practice for most of the pharmaceutical companies to issue antibiotics that may no longer be capable or lacking regulatory approval [26]. Evidence shows that increased antibiotic use may result in a positive association with a higher prevalence of resistant microorganisms, while reduced antibiotic use showed lower resistance rates. There is clear evidence that patients historically treated with antibiotics are more likely to have antibiotic resistance [20]. Further, readministration of antibiotics from the initial cycle accelerates resistance mechanisms [27]. Antibiotics encourage selective pressure for bacteria to evolve when administered frequently or irrationally. Individuals and states play a role in the evolution of antibiotic resistance [20]. For example, Clarithromycin consumption and its resistance similarly increased fourfold in Japan between 1993 and 2000 in comparison to other countries [28].

\section{Conclusion}

Antibiotics are extensively used both on human and animal health practices in developed and developing countries of the world mainly for treatment and control of various diseases. However the use, misuse and overuse of these medicines contributed favorable conditions for the emergence, occurrence and development of antibiotic resistant bacteria. Similarly, the other factor which contributes for includes: Subtherapeutic doses, non-laboratory oriented antibiotic therapy, use of ineffective drugs and poor storage of drugs. Antibiotic resistance is all time at peak level in all the parts of the world. Despite measures taken by some member states of WHO, antibiotic use in humans, animals as well as agriculture is increasing. The high economic burden in the healthcare sector has become a burning issue, due to extended hospital stays, isolation wards, stringent infection control measures and treatment failures. The public health leaders should establish a pan surveillance system coordinated at national and international levels, ongoing analysis and a mandatory reporting system for antibiotic resistance. Both domestic and global policies need to be conventional and adheredto to stop the overuse and misuse of antibiotics.

\section{References}

1. Gaynes, R. The Discovery of Penicillin-New Insights after More Than 75 Years of Clinical Use. Emerg. Infect. Dis. 2017, 23, 849853. [CrossRef]

2. Shallcross, L.J.; Howard, S.J.; Fowler, T.; Davies, S.C. Tackling the threat of antimicrobial resistance: From policy to sustainable action. Philos. Trans. R. Soc. Lond. B Biol. Sci. 2015, 370, 20140082. [CrossRef] [PubMed]

3. Laxminarayan, R.; Duse, A.; Wattal, C.; Zaidi, A.K.M.; Wertheim, H.F.L.; Sumpradit, N.; Vlieghe, E.; Hara, G.L.; Gould, I.M.; Goossens, H.; et al. Antibiotic resistance-the need for global solutions. Lancet Infect. Dis. 2013, 13, 1057-1098. [CrossRef]

4. Cassini, A.; Högberg, D.L.; Plachouras, D.; Quattrocchi, A.; Hoxha, A.; Simonsen, G.N.; Colomb-Cotinat, M.; Kretzschmar, M.E.; Devleesschauwer, B.; Cecchini, M.; et al. Burden of the AMR Collaborative Group. Attributable deaths and disabilityadjusted life-years caused by infections with antibiotic-resistant bacteria in the EU and the European Economic Area in 2015: A population-level modelling analysis. Lancet Infect. Dis. 2019, 19 55-56. [CrossRef]

5. Gajdács, M.; Urbán, E. Comparative Epidemiology and Resistance Trends of Proteae in Urinary Tract Infections of Inpatients and Outpatients: A 10-Year Retrospective Study. Antibiotics 2019, 8, 91. [CrossRef] [PubMed]

6. O'Neill, J.AntimicrobialResistance: TacklingaCrisis for the Health and Wealth of Nations. Available online: https: //amrreview.org/sites/default/files/AMRReviewPaper- 
Tacklingacrisisforthehealthandwealthofnations_1.pdf (accessed on 18 August 2019).

7. World Health Organisation. Antimicrobial Resistance: Global Report on Surveillance; WHO: Geneva, Switzerland, 2014; pp. 1256. Available online: http://apps.who.int/iris/bitstream /10665/112642/1/9789241564748_eng.pdf? ua=1 (accessed on 18 August 2019).

8. ECDC/EMEA Joint Technical Report (2009). The Bacterial Challenge: Time to React. Available online: http://ecdc.europa.eu/en/publications/Publications/0909_TER_ The_Bacterial_Challenge_Time_to_React.pdf (accessed on 18 August 2019).

9. $C D C$ Antibiotic/Antimicrobial Resistance (AR/AMR). Available online: https://www.cdc.gov/drugresistance/ biggest_threats. html (accessed on 18 August 2019).

10. Guardabasse L. and Courvalin P. Modes of antimicrobial action and mechanisms of bacterial resistance. Aarestrup, F. M., Antimicrobial resistance in bacteria of animal originChap 1.ASM Press, Washington DC. 2006.

11. Spellberg MD. chief medical officer of the Los Angeles County+University of Southern California (LAC+USC) Medical Center and professor of medicine and associate dean for clinical affairs at the Keck School of Medicine of USC. 2011.

12. Young K D. Peptidoglycan. In Wiley Online Library. Retrieved from http://www.els.net/WileyCDA/ElsArticle/refld-a0000702. html.2011.

13. World Health Organization (WHO). Tackling antibiotic resistance from a food safety perspective in Europe. WHO Library Cataloguing in Publication Data. Copenhagen, Denmark. 2011.

14. Denyer SP, Hodges NA, Gorman, SP and Gilmore BF. Hugo and Russell Pharmaceutical Microbiology (8th Edition). WileyBlackwell Publishing House, NewDelhi, India, 2011; 200229.

15. Smith D, Dushoff J, Morris J. Agricultural antibiotics and human health. PloS Med. 2005; 2(8): 232.

16. Levin BR.The population genetics of antibiotic resistance. Clin. Infect.2007; 24: 9-16.
17. Amenu D. Antimicrobial resistance for enteric pathogens isolated from acute gastro-enteritis patients, 2014.

18. Clewell D. B. Antibiotic resistance plasmids in bacteria.In Wiley Online Library.Retrieved from http://www.els.net/WileyCDA/ ElsArticle/refld-a0001491.html.2014

19. Courvalin P. Antimicrobial drug resistance: prediction is very difficult, especially about the future. Emerg.Inf. Dis.2005; 11(10).

20. Laxminarayan R, Brown GM: Economics of antibiotic resistance: A theory of optimal use . J Environ Econ Manage. 2001, 42:183206. 10.1006/jeem.2000.1156

21. Lipp EK, Huq A, Colwell RR: Effects of global climate on infectious disease: The cholera model . Clin Microbiol Rev. 2002, 15:757-770. 10.1128/CMR.15.4.757-770.2002

22. Fact sheet 2016- Antibiotic resistance. (2017). Accessed: 16 June: http://www.who.int/mediacentre/factsheets/antibioticresistance/en/..

23. Aminov RI, Mackie RI: Evolution and ecology of antibiotic resistance genes. FEMS Microbiol Lett. 2007, 271:147-161. 10.1111/j.1574-6968.2007.00757.x

24. Freire-Moran L, Aronsson B, Manz C, et al.: Critical shortage of new antibiotics in development against multidrug-resistant bacteria-Time to react is now. Drug Resist Updat. 2011, 14:118-124. 10.1016/j.drup.2011.02.003

25. Lowy FD: Antimicrobial resistance: the example of Staphylococcus aureus. J Clin Invest. 2003, 111:1265-1273. $10.1172 / \mathrm{JCl} 18535$

26. Levy SB, Marshall B: Antibacterial resistance worldwide: causes, challenges and responses.Nat Med. 2004, 10:122-129. 10.1038/nm1145

27. Anderson RM, May R: Infectious diseases of humans. Oxford. Publication Google, 1991.

28. Perez Aldana L, Kato $M$, Nakagawa $S$, et al.: The relationship between consumption of antimicrobial agents and the prevalence of primary Helicobacter pylori resistance. Helicobacter. 2002, 7:306-309. 10.1046/j.1523-5378.2002. 00096.x 